\title{
CEPHALOTHORACOPAGUS JANICEPS MONOSYMMETROS CONJOINED TWINS
}

Nirmala Sharma, Sangeeta Saxena, Kanaram, Anand Sharma, Shashi Sharma

1. Associate Professor. Department of Obstetrics \& Gynaecology, Govt. Medical College, Kota. Rajasthan.

2. Associate Professor. Department of Radiology, Govt. Medical College, Kota. Rajasthan.

3. PG Resident. Department of Obstetrics \& Gynaecology, Govt. Medical College, Kota. Rajasthan.

4. Senior Medical Officer. Department of Medicine, Govt. Medical College, Kota. Rajasthan.

5. Consultant. Department of Obstetrics \& Gynaecology.

\section{CORRESPONDING AUTHOR}

Dr. Nirmala Sharma

227/II Doctor's Quarter,

M.B.S. Hospital Campus, Nayapura,

KOTA-324001, Rajasthan, India

E-mail: nirmala_gynae@yahoo.co.in

Ph: 00919414186695

CAPSULE: Case of Cephalothoracopagus janiceps monosymmetros detected at 24 week pregnancy by antenatal ultrasound. Among the Cephalothoracopagus twins, this case comes in extremely rare category due to following features : (a) presence of separate hearts (b) male sex (c) bony fusion at the level of the base of skull. The pregnancy was terminated after proper counseling.

KEY WORDS: conjoined; twins; Cephalothoracopagus janiceps monosymmetros

INTRODUCTION: Conjoined twinning is one of the most fascinating human malformations and these cases often raise public curiosity. The existence of conjoined twins has raised many artistic and philosophic questions throughout history, as, for example, whether these twins possess one soul or two. The ancient pantheon of monstrous gods may be regarded as the oldest classification of human monstrosities and their representation as the oldest record.

Conjoined twinning is a very rare abnormality, which occurs in one of every 100 sets of monozygotic twins and in one of every 50000 to 100000 births. The twins are monozygotic and do not complete division of the embryonic disc at gestational days 13-15. In broad terms, conjoined twins may be regarded as a doubling anomaly. The later the incomplete embryologic separation occurs, the higher the likelihood of a complicated fusion.

Conjoined twins are classified according to their most prominent site of connection by using the suffix pagus (fixed). The most widely accepted classification was given by Spencer. Cephalothoracopagus is a very rare form of conjoined twinning, which occurs in one of every million births and in one of every 58 sets of conjoined twins. Classic Cephalothoracopagus twins are joined from the top of the head to the umbilicus, sharing a single foregut as well as two relatively normal hearts. The intermediate cases share either a single, very abnormal heart, or double aortic arches.

Here we present a classic case of Cephalothoracopagus janiceps monosymmetros diagnosed at 24 weeks gestation. Antenatal routine ultrasound demonstrated janiceps conjoined male twins with a single fused cranial vault, duplicated cerebra, two faces (one well formed and other rudimentary), fused thoraces, two hearts, two completely separate spines, eight limbs and polyhydramnios. 
CASE REPORT: A 30-years-old multigravida at 24-weeks gestation underwent a routine obstetric ultrasound that revealed a foetus with an unusually large head and thorax, two separate pulsatile hearts and multiple limbs and polyhydramnios. The patient had a married life of 11 years. Her only child was a female of 8 years. She had no history of any miscarriage or any infertility treatment. There was no history of consanguinity, previous twinning or congenital malformation. She denied any history of diabetes, hypertension, recent infection or ovulation-induction medication or any other drug use.

The sonographic examination revealed the twin fetuses fused from heads up to the level of umbilicus. The cranial vaults were fused with partially fused cerebra and separate posterior fossae. One face was well formed with two eyeballs (however hypotelorism was noted), and a posterior rudimentary face was present with fused ears and a slit like eyeball (cyclopia). Spines were separate and converged at base of skull. Thoraces were fused with two separate hearts. Four kidneys and two separate bladders were seen. Two pairs of upper and two pairs of lower limbs (total 8 limbs) were present. Femur length of both fetuses corresponded to 24 weeks of gestation. Single three vessel umbilical cord with single anterior placenta (low lying placenta previa type II) was seen. Polyhydramnios $(\mathrm{AFI}=41 \mathrm{Cms}$.) was present. On the basis of sonographic appearances the conjoined twin fetuses were labeled as Cephalothoracopagus janiceps monosymmetros.

After proper counseling, the couple opted for the pregnancy termination. The pregnancy termination was performed via cesarean section. The delivered fetus confirmed our diagnosis of the conjoined twins, male Cephalothoracopagus janiceps monosymmetros (fused head with only one of the face well developed, the opposite one being rudimentary). The birth weight of the delivered twins was 1100 grams and the placenta weighed 250 gms. The twins showed heart rates of 60 and $65 \mathrm{bpm}$. The Apgar score at birth was 3 . The neonate died about 45 minutes after delivery. Postmortem radiography and CT of the twins was done and reformatted scans were taken confirming the pattern of bony fusion of the twins at the level of base of the skull.

DISCUSSION: According to the "fission" hypothesis, monozygotic or identical, twins from when a single fertilized egg splits into two embryos; conjoined twins are monozygotic multiples that do not fully separate from each other. The phenomenon occurs at the blastula stage, between the 13th and 15th day after fertilization. At this time. the cells of the inner mass are totipotent and are capable of forming two normal individuals if they split equally, resulting in identical monozygotic twins. When incomplete separation occurs, conjoined twins result. Moreover, incomplete division of the embryo is associated with inhibition of complete differentiation of various organ systems, thus resulting in shared, incompletely developed organs. It has recently been proposed that conjoined twins result rather from secondary fusion of two separate embryos. This hypothesis acknowledges that the intact ectoderm of an embryo will not fuse and that the embryonic disks could unite only at locations in which the ectoderm is normally absent or normally programmed to fuse or break down. Like all monozygotic twins, conjoined twins are always the same sex, both male or both female. It is estimated that $70 \%$ of conjoined twins are female.

The earliest antenatal diagnosis of cephalothracopagus twins reported in the literature was made by vaginal ultrasound at eight weeks gestation. A false-positive result in the first trimester may result from the close proximity of the fetuses. Therefore, a definitive diagnosis with conventional ultrasound is generally made only in the early third trimester, when a 
detailed assessment of the degree of fusion can be made. 3D ultrasound employed at ten weeks gestation can generate accurate, surface rendered images of the twins assessing the anatomical relationship of the craniofacial structures, fetal skeleton, spine and thorax. 3D power Doppler can be used for vascular anatomy mapping at the conjoined site. Post-mortem radiography and 2D or 3D multi-detector row computed tomography (CT) are supportive. In our case, we have shown interesting morphologic date concerning a rare and fascinating configuration of conjoined twinning called janiceps (Cephalothoracopagus Symmetricus) using antenatal conventional and color Doppler ultrasound and confirming the findings by postmortem radiography and CT.

Cephalothoracopagus janiceps refers to twins with fused head and thorax; the single fused head has two "hemifaces" (one hemiface from each twin) each looking in opposite directions. The term janiceps is derived from Janus, the two-faced Roman God. When the two faces are identical and symmetrical, this is called cephalothoracopagus janiceps disymmetros. In cases of symmetrical janiceps disymmetros, the orientations of the two notochordal axes are perfectly ventroventral and the two faces on opposite sides of the head are identical and apparently normal. When the two faces are dissimilar and only one normal face can be seen along with a second reduced face showing varying degrees of completeness, this is called cephalothoracopagus janiceps monosymmetros. In cases of asymmetrical janiceps monosymmetros, the greater face remains normal and the duplicated axial orientations converge in the plane of the lesser partial face resulting in incomplete facial features such as a single naris, cyclopic eyes, synoptic ears, a proboscis or two small eyes in a single palpebral fissure. The present case is typical of cephalothoracopagus janiceps monosymmetros.

\section{REFERENCES :}

1. Jones KL. Smith's Recognizable Patterns of Human Malformation (5th edn). W.B. Saunders: Philadelphia, PA, 1997;656.

2. Edmonds LD, Layde PM. Conjoined twins in the United States, 1970v1977. Teratology 1982; 25: 301-308.

3. Slager UT, Anderson VM, Handmaker SD. Cephalothoracopagus janiceps malformation. A contribution to the pathogenesis of cerebral malformation. Arch Neurol 1981; 38: 103-108.

4. Spencer R. Conjoined Twins : the oretical embryologic basis. Teratology 1992; 45 : 591602.

5. Barr M, Jr. Facial duplication : case, review, and embryo genesis. Teratology 1982; 25 : 153-159.

6. Spitz L, Kiely E. Conjoined twins. JAMA 2003; 289 : 1307-1310

7. Spencer R. Theoretical and analytical embryology of conjoined twins, part I : embryongenesis. Clin Anat 2000; 13 : 36-53.

8. Lam YH, Sin SY, Lam C, Lee CP, Tang MH, Tse HY. Prenatal sonographic diagnosis of conjoined twins in the first trimester : two case reports. Ultrasound Obstet Gynecol 1998; $11: 289-291$.

9. Weiss JL, Devine PC. False positive diagnosis of conjoined twins in the first trimester. Ultrasound Obstet Gynecol 2002; 20: 516-521.

10. Maymon R, Halperin R, Weinraub Z, Herman A, Schneider D. Three-dimensional transvaginal sonography of conjoined twins at 10 weeks : a case report. Ultrasound Obstet Gynecol 1998; $11: 292-294$. 
11. Maymon R, Jauniaux E. Screening for pregnancy abnormalities. In: Textbook of Perinatal Medicine, Kurjak A (ed). The Parthenon Publishing Group: Carnforth, 1998; 571-586.

12. Bega G, Wapner R, Lev-Toaff A, Kuhlman K. Diagnosis of conjoined twins at 10 weeks using three-dimensional ultrasound: a case report. Ultrasound Obstet Gynecol 2000; 16: 388-390.

13. Merz E, Bahlmann F, Weber G, Miric-Tesanic D. Fetal malformations: assessment by three-dimensional ultrasound in the surface mode. In: 3-D Ultrasonography in Obstetrics and Gynecology, Merz E(ed). Lippincott Williams \& Wilkins:Philadelphia, PA, 1998; 109-119.

14. Slager UT, Anderson VM, Handmaker SD. Cephalothoracopagus janiceps malformation. A contribution to the pathogenesis of cerebral malformation. Arch Neurol 1981; 38: 103-108.

15. Wedberg R. Kaplan C, Leoold G, Porreco R, Resnik R, Benirschke K. Cephalothoracopagus (Janiceps) twinning. Obstet Gynecol 1979;54:392-396

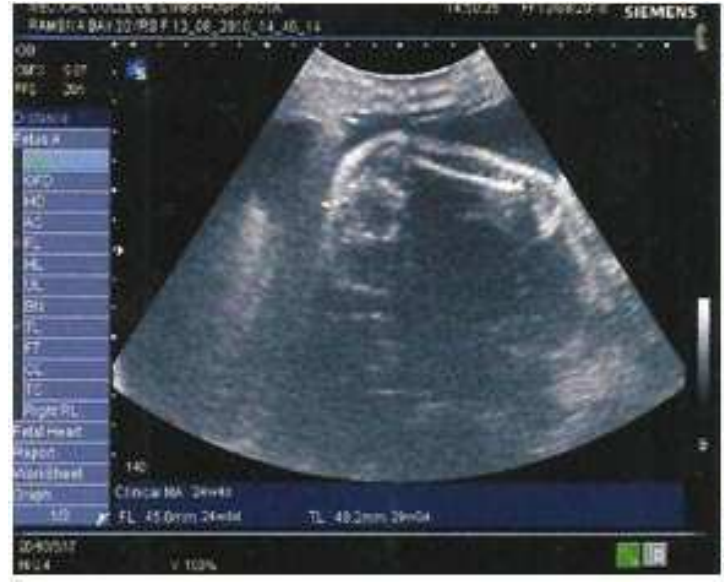

Fig. 1 Femur length corresponding to 24 separate weeks of gestation

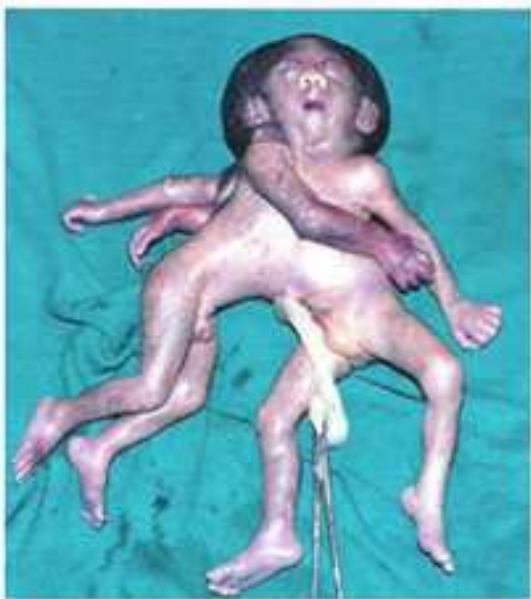

Fig. 3 Postnatal photograph of the cephalothoracopagus janiceps monosymmetros conjoined twins

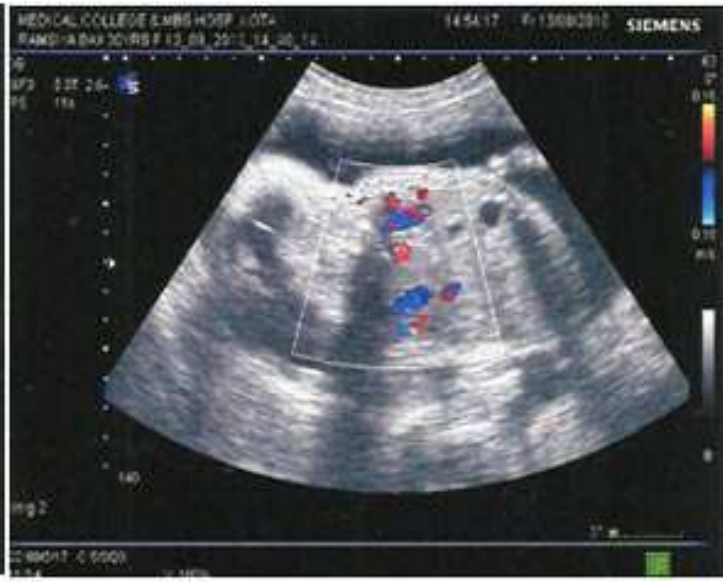

Fig. 2 Color Doppler picture showing two hearts

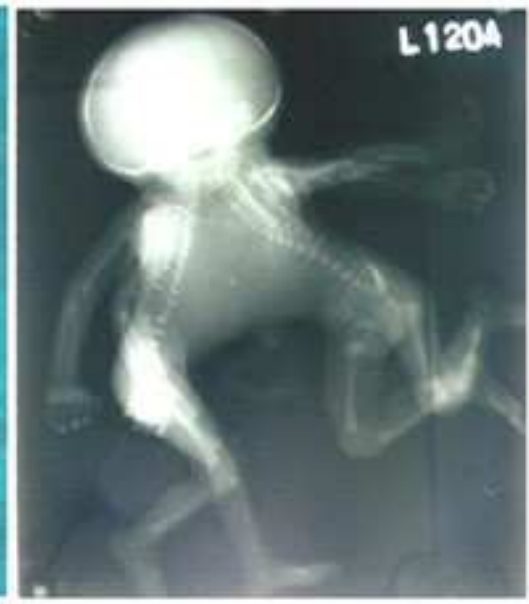

Fig. 4 Postnatal radiograph of the twins 


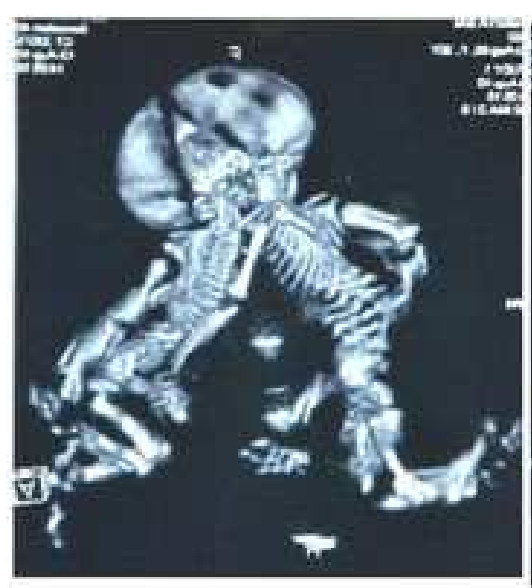

Fig $5(a)$

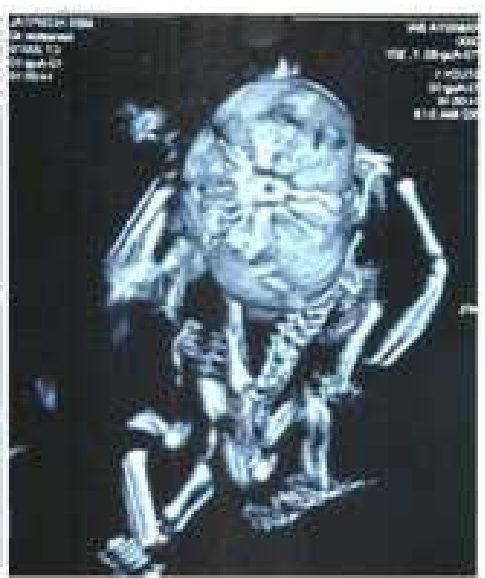

Fig 5(b)

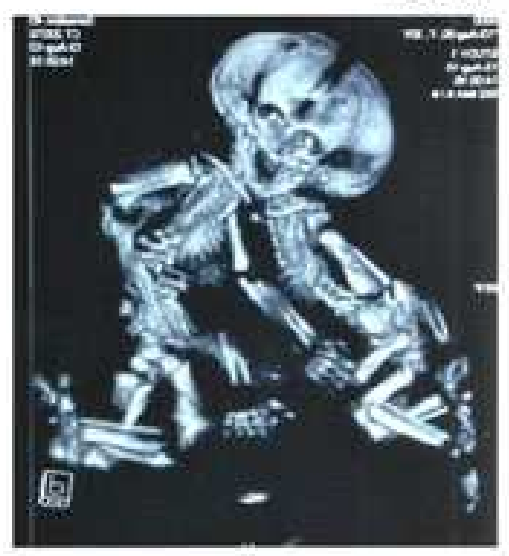

Fig 5(c)

Fig. 5 (a,b,c) Postnatal reformatted CT scans of the twins showing the pattern of bony fusion 